\title{
FACTOR V LEIDEN DISTRIBUTION - COULD IT SHED SOME LIGHT ON THE PRE-HISTORY OF EUROPE AND THE NEAR EAST?
}

\author{
Marian Simka', Paweł Latacz² \\ 'Outpatient Department of Angiology, Pszczyna, Poland \\ ¿University Hospital, Kraków, Poland
}

\author{
REVIEW PAPER \\ Phlebological Review 2016; 24, 2-3: 40-45 \\ DOl: https://doi.org/10.5114/pr.2016.65518
}

Submitted: 30.05 .2016

Accepted: 23.08.2016

\section{ADDRESS FOR CORRESPONDENCE \\ Marian Simka \\ Department of Nursing College of Applied \\ Sciences \\ Królowej Jadwigi 18, 41-704 Ruda Śląska \\ e-mail: mariansimka@poczta.onet.pl}

\begin{abstract}
Polymorphism of clotting factor V, comprising Arg506Gln substitution in the factor molecule, commonly known as Factor $V$ Leiden, represents the most common herAlthough it is suggested that this mutation is associated with a survival advantage the facilitated the spread of this polymorphism in the human population, in high prevalence of FV Leiden in some countries. Instead, we propose that cultural, climatic, and geographic factors played a role. Taking into account the current distribution of FV Leiden polymorphism and the results of recent assessments of pre-historic human DNA, we suggest that actually the origin of FV Leiden mutation did not occur in the Near East, as is widely believed, but rather in a small isolated population of so-called Basal Eurasians, probably in northern Africa. This founder group probably migrated to the Near East during the Younger Dryas, a geological period associated with climate cooling. Here, they mixed with local people; still Factor V Leiden mutation remained very prevalent in this population. The invention of agriculture, which took place approximately 2,000 years later, gave the descendants of Basal Eurasians an enormous advantage over hunter-gatherers, and probably enabled a successful spread of FV Leiden polymorphism to Europe, Central Asia, and towards the Indian subcontinent.
\end{abstract}

Key words: Factor V Leiden, survival advantage, Basal Eurasians.
Pathological polymorphism of clotting factor $\mathrm{V}$, comprising Arg506Gln substitution in the factor $\mathrm{V}$ molecule, is commonly referred to as Factor V Leiden (FV Leiden). This substitution of a single amino acid results in reduced response to the activated protein $\mathrm{C}$ because Arg506 is the cleavage site for activated protein $\mathrm{C}$ on the activated factor $\mathrm{V}$ molecule. Factor $\mathrm{V}$ Leiden mutation is associated with an increased risk of venous thrombosis, seven-fold higher in heterozygous individuals and 80-fold higher in homozygous ones. Interestingly, this increased risk applies only to venous thromboembolism and does not concern arterial thrombosis [1]. Factor V Leiden is not the only known pathological polymorphism of clotting factor V. For example, a rare polymorphism, FV Cambridge, comprises Arg306Thr substitution, and FV Hong Kong, which is found primarily in southeastern Asians an Arg306Gly substitution [2]. There are also other, less known polymorphisms of this clotting factor [3-5].

Factor V Leiden, although associated with thrombotic burden, is very common in Europe, the Near and Middle East, and also in countries that were colonised by Europeans, especially those of Germanic origin (such as:
North America and Australia). Therefore, some researchers speculated that this polymorphism presents with an unknown survival advantage that has facilitated the spread of this mutation in the human population. In this review we will argue against such a simple Darwinian evolutionary mechanism responsible for high prevalence of FV Leiden in some countries. Also, we will point out cultural, climatic, and geographic factors, which could possibly play a role. Finally, we will present some - of as yet unsolved - problems associated with the pre-history of Europe and the Near East, which potentially could be elucidated by studying current distribution of FV Leiden.

\section{Current distribution of FV Leiden polymorphism}

Prevalence of FV Leiden in general populations differs widely between countries. It represents the most common heritable risk factor for thrombotic events in Indo-Europeans and some Semitic nations (Arabs and Jews). Prevalence of FV Leiden in the general population is the highest in the Near East, and in some countries of 


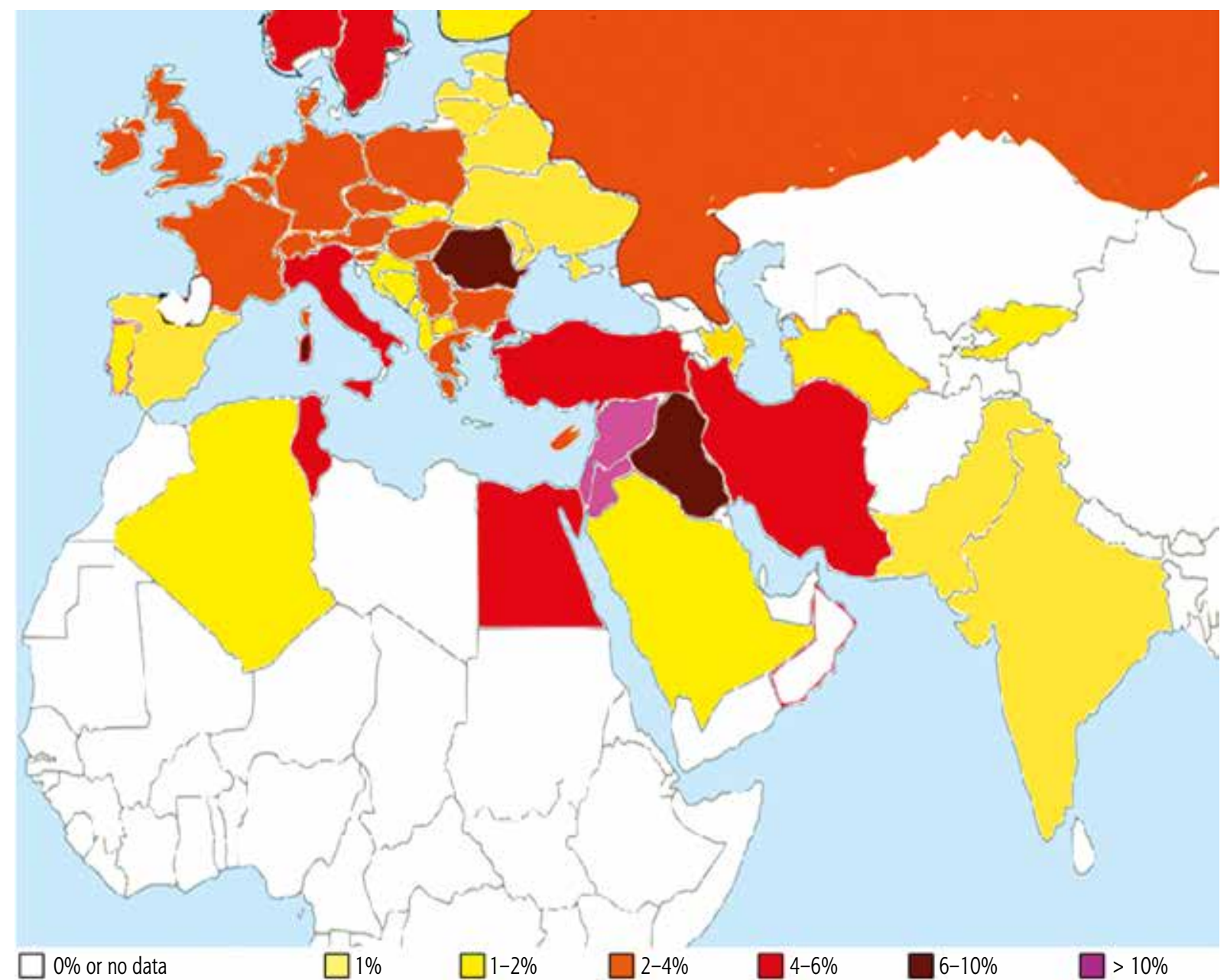

Fig. 1. Current distribution of Factor V Leiden polymorphism

this region (Lebanon, Palestine, and Syria) it is as high as $12-27 \%[6,7]$. In Europe the average prevalence of FV Leiden in general population is at the level of $3.5 \%$, but it is also unevenly distributed, with a higher frequency in northern and southeastern Europe, and lower in western and eastern Europe (Fig. 1) [8]. Interestingly, FV Leiden mutation is almost completely absent in the Basques, an indigenous ethnic group inhabiting the region located around the western end of the Pyrenees (north Spain and south-western France) [9, 10]. Similarly, this polymorphism is not found in East Asia, sub-Saharan Africa, among Greenland Eskimos and indigenous populations of the Americas, Australia, and Polynesia [6, 11, 12].

\section{Origins of FV Leiden mutation}

Zivelin et al. studied 117 Caucasians who were homozygous for FV Leiden mutation and concluded that this polymorphism most likely $\left(p<10^{-6}\right)$ arose as a single event. An estimation of probable time for the origin of FV Leiden mutation, based on analysis of two exons of this gene, revealed that it occurred either 21,000 or 34,000 years ago, with the former time being more likely [13]. Many scientists suggested that a relative hypercoagulability in FV individuals might be advantageous in a case of severe bleeding related to trauma or delivery. Other potential evolutionary advantages associated with FV Leiden mutation, which were summarised by van Mens et al., include: less menstrual blood loss, decreased risk of intracranial bleeding, a milder clinical course of haemophilia, lower mortality in the case of sepsis, higher survival in acute respiratory distress syndrome, decreased risk of diabetic nephropathy, improved embryo implantation, higher sperm count, and higher fecundity in females [14-16].

Although theoretically plausible, in our opinion most of these mechanisms are not likely to have any evolutionary effect in pre-historic (i.e. before a writing system was invented) humans. For example, less menstrual blood loss was unlikely to play relevant role in pre-historic humans, since those females, similarly to present day women belonging to uneducated tribes in Africa, were likely to 
menstruate rather infrequently, due to numerous pregnancies followed by several years of lactation. Non-traumatic fatal intracranial bleeding, such as the rupture of cerebral aneurysm, nowadays represents a very rare cause of death, and also in the past it was probably a sporadic event. Haemophilic individuals were very unlikely to survive to adult age in pre-historic times. Acute respiratory distress syndrome and diabetic nephropathy represent clinical challenges of our era but not of pre-history. Also, a higher sperm count can be advantageous in some animals, but not in humans (perhaps with the exception of a theoretical strictly mono- or polygamic society, which is not the case here). We believe that only two of these mechanisms could possibly play a role: reduced bleeding in case of trauma and decreased sepsis-associated mortality. Regarding the first potential advantage, one can imagine that an individual with less severe bleeding could more easily survive an accident. Still, in pre-historic times probably most life-threatening traumas resulted from fighting with other humans (although there are no written records coming from that time, it is likely that behaviour of our pre-historic ancestors was similar to currently described customs of hunter-gatherer tribes of Papua, the Kalahari Desert, and the Amazon Jungle [17]). And while even $10-20 \%$ of mortalities in human pre-history, and also in these uncivilised tribes, resulted from homicide, a brutish way of killing probably gave no survival advantage for FV Leiden carriers. It should also be assumed that any potential survival benefit associated with relative hypercoagulability would be reduced by an increased mortality due to venous thromboembolism, which is often associated with non-fatal trauma. Regarding the second potential benefit associated with FV Leiden mutation - a relative resistance to sepsis - it should be remembered that infectious diseases became a real problem for humans only after domestication of animals and introduction of agriculture, when people started to live in groups large enough to enable an infectious disease to stay active in the population (it is not possible in a small group of hunter-gatherers, where disease either kills all members of such a group, or all survivors become resistant; in both cases the disease can no longer attack humans, given that there is no animal reservoir of the microorganisms). Thus, during at least half of the history of FV Leiden: between 21,000 years ago (origin of this polymorphism) and 9,500 years ago (when agriculture and pastoralism were invented) this potential mechanism could not be effective. Other non-infectious cases of sepsis, which represent an important source of mortality for present day humans (primarily elderly ones) are of unclear importance for pre-historic hunter-gatherers. Also, even if some researchers found an advantage associated with FV Leiden mutation in sepsis patients [2], others were unable to demonstrate such an effect [18]. Importantly, population studies did not reveal a survival advantage in FV Leiden mutation carriers with sepsis
$[19,20]$. Thus, in our opinion FV Leiden represents rather neutral mutation in terms of evolutionary advantage. But if FV Leiden were indeed such a neutral polymorphism, there should have been other mechanisms responsible for the very high prevalence of this mutation in some populations and low in the others. Still, we should look for these mechanisms outside of biology, focusing instead on history and geography.

\section{The Basques}

As has been already mentioned, FV Leiden polymorphism is not found among the Basques $[9,10]$. The Basques represent a unique ethnic group, speaking a nonIndo-European language. Basque language (Euskara) is not linked to any contemporary existing tongue and is believed to be the only remnant of languages spoken in Europe before Neolithic migration of farmers, who introduced to Europe not only domestic animals and crops, but also Indo-European languages. For a long time the Basques were thought to be genetic descendants of pre-agricultural Europeans, with no significant genetic admixture of migrants from the Near East. But recent genetic investigations of ancient human remnants from a cave in Sierra Atapuerca (Spain) have not only revealed that people inhabiting this cave 5500-3500 years ago were genetically similar to early farmers from other parts of southern Europe, but also that their genetic pool was very close to current Basques [21]. So, why is FV Leiden mutation not found among the Basques but is quite common in other parts of Europe, while other genes are shared by Basques and other Europeans? This paradox can be explained by a phenomenon referred to as clinal genetic admixture. If a migrating group of people does not exterminate totally the local population, and there is some intermarriage, a dilution of the genes of the migrating group occurs. Neolithic expansion of agriculture into Europe consisted of hundreds of such intermarriages and gene dilutions, and finally in the most remote areas, such as the Basque country, most of the genes were derived from local population and only a small fraction from the invaders (we clearly see this phenomenon in Ireland, also located at the periphery of Europe) [22]. Early farmers migrated to Europe from Anatolia (nowadays: eastern Turkey) [23], and when the wave of migrating people and agriculture had reached southwestern Europe, the original Anatolian genepool must have been significantly diluted by the genes of hunter-gatherers previously residing in Europe. Most likely there were many FV Leiden carriers between early farmers from Anatolia, since the distribution of this polymorphism in Europe suggests that this mutation spread into Europe from this location. But when the agricultural wave entered the Basque country, it is possible that FV Leiden genes were "diluted" to such a level that not a single individual with this mutation arrived in this area. There might be more such 
places with no FV Leiden polymorphism in remote locations throughout pre-historic Europe, but in the Basque country, because of its geographic (mountainous terrain, far from trading routes) and cultural (language) isolation, FV Leiden polymorphism has not been introduced by subsequent invaders in historic times (such as: the Romans, Goths, or Arabs) [21, 24]. By contrast, if early farmers were migrating over long distances and consequently there was only a little clinal genetic admixture, in such areas we should expect a higher frequency of the genes of these early farmers, including FV Leiden polymorphism. Indeed, in southern Scandinavia FV Leiden is highly prevalent, and archaeological investigations have revealed that many farmers arrived to this area directly from southern Europe, and in addition there was little intermarriage between these migrants and local huntergatherers [24, 25].

There is also another consequence of the Basque phenomenon: if a lack of FV Leiden polymorphism among the Basques resulted from clinal genetic admixture, it suggests that before Neolithic migration of farmers from the Near East, the FV Leiden gene was not present among European hunter-gatherers. If our hypothesis that indeed there was no FV Leiden polymorphism in Europe before Neolithic migration from Anatolia is correct, this scenario would shed some light on the actual origin of this mutation and also on some important pieces of European pre-history.

\section{Where did FV Leiden actually develop?}

For the time being, most researchers believe that the location of the source of FV Leiden mutation is not very controversial. Geographic distribution of FV Leiden [6, 11 ] suggests that the founder of this mutation lived in the Near East, and the spread of FV Leiden mutation was associated with the invention of agriculture and migration of early farmers from Anatolia to Europe, Central Asia, and towards the Indian subcontinent. But this migration took place later than 9500 years ago (after the invention of agriculture), while the above-discussed genetic study [13] suggests that the founder of this mutation lived about 21,000 years ago. Also, FV Leiden mutation is almost exclusively found among speakers of Indo-European and Semitic languages. Linguists generally agree that a common language, the ancestor of the two language families, existed about 25,000 years ago [26]. This chronology is in line with the genetic timing of this polymorphism. Taking into account these genetic and linguistic presumptions, there should be a period of at least 10,000 years when people with FV Leiden mutation were living in the Near East but did not share this polymorphism with contemporary Europeans and people inhabiting other parts of the world, and simultaneously retained a high prevalence of FV Leiden polymorphism in this founder population. In our opinion, both condi- tions were difficult to meet, especially during such a long period of time and considering the geography of the Near East, which - at least theoretically - allows rather smooth transmission of the genes in any geographic direction (even if a recent study demonstrated that pre-historic inhabitants of the Jordan Valley /nowadays: Israel and Jordan/ and Zagros mountains /nowadays: western Iran/ were strongly genetically differentiated [23], in our opinion this finding could be explained by the geographic barrier formed by western edge of the Zagros). Unfortunately, there are no written records coming from such a distant past (writing was invented much later). Also, DNA is poorly preserved in warm climates, not to mention that potential archaeological material from that time is very scarce (the oldest known human remnants of a carrier of FV Leiden, about 3000 years old, come from excavations of the Urartu civilisation, nowadays eastern Turkey [27]; this Urartu individual, quite recent in terms of the discussed time perspective, cannot clarify the problem).

But we suggest that this puzzle could be solved if we assume that the population carrying FV Leiden polymorphism did not originally live in the Near East, but lived in a small isolated group elsewhere, with very limited possibility of genetic admixture, and moved into the Near East just before invention of agriculture. Such a scenario would explain the high prevalence of FV Leiden mutation in this founder population (and also in the current Near East). Also, this scenario would explain why pre-Neolithic Europe was probably free of FV Leiden polymorphism. But is such a storyline realistic? However strange, very recent genetic investigations of ancient human remnants from the Near East (researchers have extracted genetic material from the petrous bone, where DNA is better preserved) revealed that Neolithic inhabitants of the Near East derived a significant part of their genetic pool from the so-called Basal Eurasians, a hypothetical kind of ancestry that no longer exists in pure form, but has mixed into modern Europeans and other people from the Near and Middle East, South Asia, and North Africa. Basal Eurasians represent one of the hypothetical lineages that developed after the separation of non-African populations from Africans. It is estimated that about $44 \%$ of the genetic pool of early farmers from the Near East was derived from Basal Eurasians [28], and that this ancestry significantly contributed to the genetic pool of modern Europeans. Interestingly, the Basal Eurasian genome uncovered by this study had no Neanderthal admixture, which is strange, since it is the Near East where modern humans mixed with the Neanderthals [23]. Most likely, Basal Eurasians lived outside of the Near East, somewhere where there were no Neanderthals (this human species inhabited Europe and western Asia, but not Africa) and also no modern humans with sub-Saharan African genetic pool. We think that an isolated location in northern Africa seems to meet all of 
these criteria. Such an area, located between the mountains and deserts of Sahara and the Mediterranean Sea, would allow genetic isolation, even for such a long period as 10,000 years. Thus, in our opinion it is possible that FV Leiden mutation originally developed among Basal Eurasians who lived in Africa north of Sahara. It would be interesting to investigate if this population actually carried this polymorphism. With the laboratory methods used by Lazaridis et al. [23], such research seems technically feasible.

Finally, one may ask why this hypothetical population, carrying FV Leiden polymorphism, moved from their isolated homeland in northern Africa toward the Near East? There should be something that occurred shortly before 10,000 years ago and forced these people to migrate. And there is actually a well-known potential event: the Younger Dryas. During this geological period, approximately 12,000 years ago, a dramatic climate cooling occurred, with an average temperature decline of $2-6^{\circ} \mathrm{C}$ throughout the Northern Hemisphere. During the Younger Dryas, which lasted about 1,000 years, much of Europe transformed into a cold desert. Also North Africa became extremely arid, with drying and expansion of the Sahara Desert [29]. But the Near East (particularly the Jordan Valley) remained relatively moist and provided a potential refuge for people who were driven out of their homeland by the sudden climate change $[30,31]$. The invention of agriculture and animal husbandry, which occurred in the Near East some 2,000 years later among a population carrying a substantial genetic pool of Basal Eurasians [23, 28], gave those people an enormous advantage over hunter-gatherers and probably enabled a successful spread of FV Leiden polymorphism.

\section{The authors declare no conflict of interest.}

\section{References}

1. Mann K.G., Kalafatis M. Factor V: a combination of Dr Jekyll and Mr Hyde. Blood 2003; 101: 20-30.

2. Kerlin B.A., Yan S.B., Iserman B.H., Brandt J.T., Sood R., Basson B.R. Survival advantage associated with heterozygous factor $\mathrm{V}$ Leiden mutation in patients with severe sepsis and in mouse endotoxemia. Blood 2003; 102: 3085-3092.

3. Guzmán N., Larama G., Ávila A., Salazar L.A. Three novel variants in the coagulation factor $\mathrm{V}$ gene associated with deep venous thrombosis in Chilean patients with Amerindian ethnic background. Clin Chim Acta 2015; 444: 24-28.

4. Pezeshkpoor B., Castoldi E., Mahler A., Hanel D., Müller J., Hamedani N.S., Biswas A., Oldenburg J., Pavlova A. Identification and functional characterization of a novel F5 mutation (Ala512Val, FVB onn) associated with activated protein C resistance. J Thromb Haemost 2016; 14: 1353-1363.

5. Wijk van R., Montefusco M.C., Duga S., Asselta R. Coexistence of a novel homozygous nonsense mutation in exon 13 of the factor $\mathrm{V}$ gene with the homozygous Leiden mutation in two unrelated patients with severe factor $\mathrm{V}$ deficiency. Br J Hematol 2001; 114: 871-874.
6. Jadaon M.M. Epidemiology of activated protein resistance and factor V Leiden mutation in the Mediterranean region. Mediterr J Hematol Infect Dis 2011; 3: e2011037.

7. Irani-Hakime N., Tamim H., Kreidy R., Almawi W.Y. The prevalence of factor V R506Q mutation-Leiden among apparently healthy Lebanese. Am J Hematol 2000; 65: 45-49.

8. Clark S.C., Adler G., Salkie N.N. Allele frequency distribution of $1691 \mathrm{G}>\mathrm{A}$ (which confers Factor V Leiden) across Europe, including Slavic populations. J Appl Genetics 2013; 54: 441-446.

9. Bauduer F., Degioanni A., Dutour O. Genetic hematology of French Basques: recent data about this peculiar Pyrenean people. Int J Anthropol 2005; 20: 331-342.

10. Bauduer F., Zivelin A., Ducout L., Shpringer E., Selgsohn U. The prevalence of factor V G1691A but not of prothrombin G2020A and methylenetetrahydrofolate reductase $\mathrm{C} 677 \mathrm{~T}$ is remarkably low in French Basques. J Thromb Haemost 2004; 2: 361-362.

11. Lucotte G., Mercier G. Population genetics of factor V Leiden in Europe. Blood Cells Mol Dis 2001; 27: 362-367.

12. de Stefano V., Chiusolo P., Paciaroni K., Leone G. Epidemiology of factor V Leiden: clinical implications. Semin Thromb Hemost 1998; 24: 367-379.

13. Zivelin A., Griffin J.H., Xu X., Pabinger I., Samama M., Conard J., Brenner B., Eldor A., Seligsohn U. A single genetic origin for a common Caucasian risk factor for venous thrombosis. Blood 1997; 89: 397-402.

14. van Mens T.E., Levi M., Middeldorp S. Evolution of factor V Leiden. Thromb Haemost 2013; 110: 23-30.

15. Franchini M., Lippi G. Factor V Leiden in women: a thrombotic risk factor or an evolutionary advantage? Semin Thromb Hemost 2011; 37: 275-279.

16. Lindqvist P.G., Dahlbäck B. Carriership of Factor V Leiden and evolutionary selection advantage. Curr Med Chem 2008; 15 : 1541-1544.

17. Diamond J. The world until yesterday. Viking Penguin, New York, USA 2012.

18. Benfield T.L., Dahl M., Nordestgaard B.G., Tybjaerg-Hansen A. Influence of the factor $\mathrm{V}$ Leiden mutation on infectious disease susceptibility and outcome: a population-based study. J Infect Dis 2005; 192: 1851-1857.

19. Heijmans B.T., Westendorp R.G., Knook D.L., Kluft C., Slagboom P.E. The risk of mortality and the factor V Leiden mutation in a population-based cohort. Thromb Haemost 1998; 80: 607-609.

20. Hille E.T., Westendorp R.G., Vandenbroucke J.P., Rosendaal F.R. Mortality and causes of death in families with the factor V Leiden mutation (resistance to activated protein C). Blood 1997; 89: 1963-1967.

21. Günther T., Valdiosera C., Malmström H., Ureña I., Rodriguez-Varela R., Sverrisdóttir Ó.O., Daskalaki E.A., Skoglund P., Naidoo T., Svensson E.M., Bermúdez de Castro J.M., CarbonellE., Dunn M., Storå J., Iriarte E., Arsuaga J.L., Carretero J.M., Götherström A., Jakobsson M. Ancient genomes link early farmers from Atapuerca in Spain to modern-day Basques. Proc Natl Acad Sci USA 2015; 112: 11917-11922.

22. Diamond J., Bellwood P. Farmers and their languages: the first expansions. Science 2003; 300: 597-603.

23. Lazaridis I., Nadel D., Rollefson G., Merrett D.C., Rohland N., Mallick S., Fernandes D., Novak M., Gamarra B., Sirak K., Connell S., Stewardson K., Harney E., Fu Q., Gonzalez-Fortes G., Jones E.R., Roodenberg S.A., Lengyel G., Bocquentin F., Gasparian B., Monge J.M., Gregg M., Eshed V., Mizrahi A.S., Meikle- 
john C, Gerritsen F., Bejenaru L., Blüher M., Campbell A., Cavalleri G., Comas D., Froguel P., Gilbert E., Kerr S.M., Kovacs P., Krause J., McGettigan D., Merrigan M., Merriwether D.A., O’Reilly S., Richards M.B., Semino O., ShamoonPour M., Stefanescu G., Stumvoll M., Tönjes A., Torroni A, Wilson J.F., Yengo L., Hovhannisyan N.A., Patterson N., Pinhasi R., Reich D. Genomic insights into the origin of farming in the ancient Near East. Nature 2016; 536: 419-424.

24. Günter T., Jakobsson M. Genes mirror migrations and cultures in prehistoric Europe - a population genomic perspective. BioRxiv 2016; 41: 115-123.

25. Skoglund P., Malmström H., Raghavan M., Storå J., Hall P., Willerslev E., Gilbert M.T., Götherström A., Jakobsson M. Origins and genetic legacy of Neolithic farmers and hunter-gatcherers in Europe. Science 2012; 336: 466-469.

26. Bomhard A.R. Toward Proto-Nostratic. A new approach to the comparison of Proto-Indo-European and Proto-Afroasiatic. John Benjamin Publishing Co. Amsterdam/Philadelphia 1984.

27. Alakoç Y.D., Aka P.S., Eğin Y., Akar N. Factor V Leiden in an Urartian, dating back to 1000 BC. Clin Appl Thromb Hemost 2010; 16: 679-683.

28. Lazaridis I., Patterson N., Mittnik A., Renaud G., Mallick S., Kirsanow K., Sudmant P.H., Schraiber J.G., Castellano S., Lipson M., Berger B., Economou C., Bollongino R., Fu Q., Bos K.I., Nordenfelt S., Li H., de Filippo C., Prüfer K., Sawyer S., Posth C., Haak W., Hallgren F., Fornander E., Rohland N., Delsate D., Francken M., Guinet J.M., Wahl J., Ayodo G., Babiker H.A., Bailliet G., Balanovska E., Balanovsky O., Barrantes R., Bedoya G., Ben-Ami H., Bene J., Berrada F., Bravi C.M., Brisighelli F., Busby G.B., Cali F., Churnosov M., Cole D.E., Corach D., Damba L., van Driem G., Dryomov S., Dugoujon J.M., Fedorova S.A., Gallego Romero I., Gubina M., Hammer M., Henn B.M., Hervig T., Hodoglugil U., Jha A.R., Karachanak-Yankova S., Khusainova R., Khusnutdinova E., Kittles R., Kivisild T., Klitz W., Kučinskas V., Kushniarevich A., Laredj L., LitvinovS., Loukidis T., Mahley R.W., Melegh B., Metspalu E., Molina J., Mountain J., Näkkäläjärvi K., Nesheva D., Nyambo T., Osipova L., Parik J., Platonov F., Posukh O., Romano V., Rothhammer F., Rudan I., Ruizbakiev R., Sahakyan H., Sajantila A., Salas A., Starikovskaya E.B., Tarekegn A., Toncheva D., Turdikulova S., Uktveryte I., Utevska O., Vasquez R., Villena M., Voevoda M., Winkler C.A., Yepiskoposyan L., Zalloua P., Zemunik T., Cooper A., Capelli C., Thomas M.G., Ruiz-Linares A., Tishkoff S.A., Singh L., Thangaraj K., Villems R., Comas D., Sukernik R., Metspalu M., Meyer M., Eichler E.E., Burger J., Slatkin M., Pääbo S., Kelso J., Reich D., Krause J. Ancient human genomes suggest three ancestral populations for present-day Europeans. Nature 2014; 513: 409-413.

29. Carlson A.E. Global Younger Dryas. Encyclopedia of Quaternary Science 2013; 3: 126-134.

30. Adams J., Otte M. Did Indo-European languages spread before farming? Curr Anthopol 1999; 40: 73-77.

31. Hartman G., Bar-Yosef O., Brittingham A., Grosman L., Munro N.D. Hunted gazelles evidence cooling, but not drying, during the Younger Dryas in the southern Levant. Proc Natl Acad Sci U S A 2016; 113: 3997-4002. 